\title{
ASSISTÊNCIA DE ENFERMAGEM EM UNIDADE DE INTERNAÇÃO NEONATAL: MEDIDAS PARA PREVENÇÃO DE INFECÇÕES HOSPITALARES*
}

\author{
Ivone Kamada ** \\ Semíramis Melani Melo Rocha ***
}

KAMADA, I.; ROCHA, S.M.M. Assistência de enfermagem em unidades de internação neonatal: medidas para prevenção de infecções hospitalares. Rev.latino-am.enfermagem, Ribeirão Preto, v. 5, n. 1, p. 37-48, janeiro 1997.

A prevenção de infecção em berçários requer cuidados com o ambiente, equipamentos, pessoal e o próprio recémnascido, pertinentes assistência de enfermagem. Frente aos problemas relacionados a infecções hospitalares encontrados, esta investigação tem por objetivo verificar a relação entre as medidas prescritivas sobre a Prevenção de Infecção e as atividades efetivas realizadas numa Unidade de Internação Neonatal. As estratégias de investigação adotadas foram a observação participante e a entrevista semi-estruturada possibilitando a coleta de dados. Pudemos ver com este trabalho que as medidas profiláticas têm que ser tomadas em conjunto, num complexo de atividades,fundamentadas em instalações e estrutura adequadas, desempenhadas por uma equipe profissional coesa, onde todos trabalhem com os mesmos objetivos. Tomá-las isoladamente não contribui para o efetivo cumprimento das prescrições.

UNITERMOS: assistência de enfermagem neonatal, infecção hospitalar, recém-nascido, berçário, neonatologia

\section{INTRODUÇÃO}

Os modelos de assistência às crianças sofreram grandes transformações através dos tempos, sobretudo nos últimos 50 anos. No início do século XX, impôs-se a instalação nas maternidades de berçários destinados a recém-nascidos face à alta taxa de mortalidade infantil por infecções e pela inexistência de equipamentos e recursos adequados (PIZZATO \& DA POIAN ${ }^{16}, 1988$ ). Tinham como objetivo o isolamento, como medida preventiva, recomendando-se mínima manipulação do recém-nascido e proibição de qualquer visita, inclusive da mãe (GORDON $^{09}$, 1984). Estes berçários vieram a ser implantados no Brasil em 1945 (LOYOLA ${ }^{12}$, 1983).

Com o parto hospitalar, a Unidade de Internação Neonatal é local onde os recém-nascidos são recebidos e têm o primeiro contato com a flora microbiana hospitalar, sendo ali colonizados. Assim, geralmente, 48 horas após o nascimento, os tecidos são invadidos por microrganismos de origem predominantemente materna. Mais tarde se instalarão microrganismos outros originários da equipe de saúde, de outras crianças e de visitantes, podendo desenvolver infecções exógenas ou por invasão adquirida (NELSON ${ }^{14}, 1983$; KLEIN ${ }^{11}$ et al, 1983).
Apesar de todo o avanço tecnológico observado nas últimas décadas, principalmente o aparecimento dos antibióticos, as infecções constituem causas importantes nos altos índices de morbi-mortalidade neonatais (SÃO PAULO $^{18}$, 1976; OLIVEIRA ${ }^{15}$, 1983). Provavelmente, aspectos sócio-econômicos-culturais contribuem para esta maioria dos hospitais brasileiros, a carência qualitativa e quantitativa de recursos materiais $e$ humanos e a precária saúde do povo (PIZZATO \& DA POIAN $^{16}, 1988$ ).

A dificuldade na limpeza do instrumental que serve como veículo, geralmente é agravada, quando ocorre superpopulação, porque quase sempre se lida com pessoal deficiente em número e comumente em qualidade; acarretando em sobrecarga para a equipe de trabalho. Assim, observa-se a quebra da técnica, não se realizando a lavagem das mãos nem a limpeza adequada do material; nem é possível afastar os portadores de processos infecciosos, porque não há substitutos para o trabalho.

A padronização das rotinas de forma sistematizada vem sendo descrita há tempos, como o primeiro manual sobre "Normas e Recomendações Hospitalares para a Atenção ao Recém-nascido a Termo e Prematuro", publicado em 1943 pela Oficina del Niño (ACADEMIA

\footnotetext{
* Resumo de Dissertação de Mestrado apresentada à Escola de Enfermagem de Ribeirão Preto da Universidade de São Paulo

** Enfermeira, Professor Assistente do Departamento de Enfermagem da Faculdade de Ciências da Saúde da Universidade de Brasília-UnB

${ }^{\star * \star}$ Enfermeira, Professor Titular do Departamento de Enfermagem Materno-infantil e Saúde Publica da Escola de Enfermagem de Ribeirão Preto da Universidade de São Paulo
} 
AMERICANA DE PEDIATRIA $\left.{ }^{01}, 1957\right)$. Nos últimos anos pouca coisa tem sido realizada nesse sentido. Alguns autores como Williams e Oliver Júnior citados por ZANON $^{22}$ (1987); ROBERTON ${ }^{17}$ (1986); CLONEY \& DONOWITZ ${ }^{07}$ (1986) e DONOWITZ ${ }^{09}(1989)$, desobrigam o uso de propés e gorros, entretanto, certos berçários continuam mantendo as prescrições antigas nos dias de hoje. Os estudos sobre infecções hospitalares em berçários estão mais centrados na descrição anátomo-patológica de casos clínicos, do que em estudos sobre a incidência e outros índices epidemiológicos ou medidas de prevenção de infecção cruzada.

A existência de rotinas para prevenção de infecções hospitalares e de pessoal em número suficiente para cumpri-las é relevante na profilaxia e controle de infecção hospitalar. Através da literatura consultada, verificamos que para a prevenção da infecção hospitalar no berçário, alguns cuidados devem ser tomados quanto ao ambiente, ao pessoal, paramentação, equipamentos e ao recém-nascido (VÉRAS ${ }^{21}$ et al, 1965; CEPENSP ${ }^{06}$ 1966; SÃO PAULO, $1976^{18}, 1981^{19}, 1991^{20}$; AMERICAN ACADEMY OF PEDIATRICS, $1954^{02} 1974^{03} 1977^{04}$; BRASIL $\left.^{05}, 1985\right)$.

A equipe de enfermagem responde por grande parte dos mecanismos de prevenção, seja em atividades administrativas quando supervisiona e faz treinamento de pessoal, seja nos cuidados prestados aos recém-nascidos. Esta situação nos levou a uma questão central: os procedimentos técnicos padronizados com o objetivo de prevenir infecções são exeqüíveis?

Dessa forma, colocamos como problema a ser investigado as medidas prescritivas de prevenção de infecções em berçários e a possibilidade delas serem executadas pela enfermagem e a equipe de saúde. A finalidade limita-se a verificar se elas são exeqüíveis, se podem ser melhoradas e onde há falhas. Pretendemos também suscitar a reflexão sobre o significado dos procedimentos prescritivos na assistência.

\section{OBJETIVO}

Verificar a relação entre as medidas prescritivas sobre a Prevenção de Infecções e as atividades efetivas realizadas numa Unidade de Internação Neonatal.

\section{METODOLOGIA}

Esta investigação é um estudo de caso descritivo que procura fornecer o conhecimento aprofundado de uma realidade delimitada, cujos resultados poderão permitir a formulação de hipóteses para o encaminhamento de outras pesquisas.

A fase exploratória consistiu em um levantamento bibliográfico realizado em trabalho anterior KAMADA $^{10}$, 1991), onde identificamos na literatura os núcleos temáticos sobre assistência de enfermagem neonatal. Dentre esses núcleos, a Prevenção de Infecção em Unidade de Internação Neonatal foi à temática de escolha para esta investigação.

\section{Local}

O estudo foi desenvolvido numa Unidade de Internação Neonatal de um hospital escola da rede pública do estado de São Paulo, que atende pacientes com procedência de várias cidades, além dos oriundos de outros estados. Atualmente, conta com 21 leitos de internação distribuídos em: 14 para recém-nascidos normais, em observação e prematuros, quatro para alto risco e três para isolamento.A planta física do berçário corresponde a $128,10 \mathrm{~m}^{2}$ da área útil (Figura 1 - ANEXO).

Quanto aos recursos humanos de enfermagem, a unidade conta com uma diretora de serviço, seis enfermeiras, 19 auxiliares, cinco atendentes, um agente administrativo e duas escriturárias. Geralmente, são escaladas quatro funcionárias no plantão da manhã, sendo pelo menos duas auxiliares, e uma ou duas enfermeiras; nos plantões da tarde, noturno, domingos e feriados esses números são reduzidos a três funcionárias e uma enfermeira.

\section{Observação}

Nossa inserção no campo foi na situação de observador participante total, onde segundo MINAYO $^{13}$ (1989), o pesquisador participa inteiramente, apresenta a maior identificação possível com o grupo estudado, mas não sai da cena do trabalho de campo. Os sujeitos da investigação não sabem que estão sendo observados e pesquisados. A idéia inicial, portanto, foi inserir o observador no campo de observação assumindo plantões juntamente com a equipe de enfermagem, visando a integração com o grupo. A observação teve como base um instrumento elaborado de acordo com a literatura consultada, já citada na introdução deste trabalho e apresentada na referencia bibliográfica ao final, destacando os pontos importantes para a prevenção de Infecção Hospitalar em Unidade de Internação Neonatal. Um Protocolo de Observação foi elaborado contendo na primeira coluna uma descrição dos procedimentos prescritos na literatura e na segunda um espaço em aberto para anotação dos mesmos procedimentos observados na coleta de dados, contendo os seguintes itens: planta física e distribuição dos berços, cuidados relativos ao ambiente, métodos de higienização, cuidados relativos ao pessoal contactante, métodos de limpeza e cuidados relativos ao recém-nascido. Cada item foi desdobrado em subitens de acordo com o encontrado na literatura. 
Como exemplo, o item 3, métodos de higienização, foi composto de 3.1, cuidados com as mãos, e 3.2, instalação de torneiras e pias. Neste trabalho, as técnicas e prescrições para. a prevenção de infecção hospitalar foram tomadas como roteiro de observação e comparadas às atividades cotidianas de uma Unidade de Internação Neonatal.

\section{Coleta de dados}

Após devidamente autorizado pela Comissão de Ética do hospital, iniciamos a coleta de dados. A atividade a ser observada era, diariamente, determinada com antecedência, a saber: higiene das mãos, uso de avental, higiene do recém-nascido, assim por diante, direcionando nossa observação e evitando acúmulo de informações, o que prejudicaria a investigação. Entretanto, estando na enfermaria, confirmávamos ou retificávamos observações feitas anteriormente. Toda observação realizada foi registrada num Diário de Campo, logo que o investigador deixava a unidade. Os registros eram feitos em fichas pautadas item por item, transcrevendo-se os dados passo a passo para a segunda coluna do Protocolo de Observações. Em anexo colocamos para exemplificar o protocolo de observação do item 01: Planta física e distribuição dos berços (ANEXO 2). A observação estendeu-se por nove meses, sendo realizada por um dos pesquisadores. Durante este período, o observador esteve em campo quatro vezes por semana, permanecendo durante 0 plantão por quatro horas. As observações foram feitas em plantões alternados, manhã, tarde e noturno e dias da semana alternados, incluindo o finais de semana.

\section{Entrevista}

$\mathrm{Na}$ medida em que as observações não eram suficientes para a coleta de dados necessários, o pesquisador realizava entrevistas. Foram entrevistadas enfermeiras, auxiliares de enfermagem e faxineira que atuam no berçário e o roteiro das entrevistas fundamentou-senas observações realizadas de tal forma a preencher as lacunas deixadas na observação. Assim, à faxineira indagou-se qual a solução utilizada na limpeza do berçário, à enfermeira, como ela realizava a educação continuada, às auxiliares de enfermagem, sobre a necessidade da lavagem das mãos entre cada cuidado prestado ao recém-nascido. Cada entrevista foi particular e específica, de acordo com um objetivo.

\section{Análise dos dados}

A análise dos dados foi realizada confrontandose os dados observados com os dados da literatura, transcritos no Protocolo de Observação. Inicial mente fez-se apenas uma verificação das semelhanças e divergências. A seguir, os mesmos foram apresentados a uma equipe de médicos e enfermeiras especialistas em neonatologia e a um grupo de estudos sobre saúde da criança e do adolescente. Os resultados encontrados foram discutidos e analisados por estes grupos e procurou.se o significado, as causas e as explicações para o dado levantado em cada item e sub-item do protocolo de observação. Estas reuniões foram gravadas, anotadas e transcritas. A seguir, após leitura cuidadosa de todo o material, os resultados e a discussão foram sintetizados e estão apresentados a seguir. O Protocolo de Observação não foi transcrito na íntegra neste artigo por falta de espaço nesta publicação. Os interessados poderão consegui-lo com os autores do trabalho e encontra-se à disposição para consulta.

\section{RESULTADOS E DISCUSSÃO}

A seguir apresentamos uma síntese das análises e interpretações dos dados levantados na. observação, confrontados com as medidas prescritivas encontradas na revisão bibliográfica para o controle. e prevenção de infecção no berçário. Esta síntese está categorizada de acordo com cada item contemplado no protocolo de observações. Nas considerações finais fazemos uma reflexão mais abrangente: sobre as possibilidades de serem observadas as medidas prescritivas de prevenção de infecções em berçários, considerando todo o contexto do berçário e mais especificamente as atribuições da enfermagem.

\subsection{Planta física e distribuição dos berços}

O berçário tem três enfermarias: a primeira com uma área útil de $25,92 \mathrm{~m}^{2}$, que atende recém-nascidos de alto risco; a segunda com área útil de $53,30 \mathrm{~m}^{2}$ alojando recém-nascidos normais e prematuros em incubadoras e a terceira com área útil de $15,60 \mathrm{~m}^{2}$, subdivida em três unidades individuais para isolamentos, tendo duas $5,10 \mathrm{~m}^{2}$ de área útil, outra $5,40 \mathrm{~m}^{2}$ e um posto de enfermagem com $9,08 \mathrm{~m}^{2}$. O número de leitos, incluindo berços, incubadoras e berço aquecido variou em dias diferentes de observação, conseqüentemente a metragem que ocupam e a distância entre eles.

Além da enfermaria estar freqüentemente sobrecarregada com número excessivo de berços ocupados, a enfermagem aproxima ou afasta os berços, para facilitar o cuidado com o recém-nascido. desta forma, de acordo com a rotina de cuidados diários, como banho, medicação, fototerapia, soroterapia, limpeza da 
enfermaria, os berços são deslocados, aproximando-se e afastando-se uns dos outros, desrespeitando a distancia mínima preconizada. Os berços unidos proporcionam à enfermagem poupar tempo e energia e maior controle do recém-nascido.

Outra questão a ser levantada referente à superlotação no berçário é a distribuição e contenção da demanda na atual organização do sistema de saúde. Não há mais assistência ao parto domiciliar e a população, em sua maioria procura assistência em hospitais da rede pública ou conveniada com o Sistema Único de Saúde. Estes, pressionados pela demanda, sobrecarregam sua capacidade de ocupação, ainda que com espaço físico e recursos humanos insuficientes, características estas não respeitadas, o que dificulta o cumprimento das prescrições. Logo, o cumprimento de manter os berços afastados aproximadamente $60 \mathrm{~cm}$ esbarra em dois obstáculos: a forma como a enfermagem organiza seu trabalho e a superlotação no berçário determinada por instância maior. Esses obstáculos têm levado a enfermagem a trabalhar em condições adversas para prevenir infecção nesse aspecto.

\subsection{Cuidados relativos ao ambiente}

A unidade conta com um aparelho de ar condicionado instalado na parede de cada enfermaria, não sendo utilizados no período de observação; um aparelho encontra-se sem a tela. O condicionador de ar parece estar sendo utilizado quando os funcionários sentem calor e se queixam do uso do avental que o acentua. Portanto, sua utilização está mais relacionada ao conforto dos funcionários do que às necessidades dos recém-nascidos. As janelas não são teladas conforme o preconizado.

\subsection{Métodos de Higienização}

\subsubsection{Cuidados com as mãos antes da entrada nas unidades de berçário}

A literatura preconiza a lavagem das mãos entre um cuidado e outro prestado ao recém-nascido, bem como evitar o uso de relógios, anéis e pulseiras, para evitar a disseminação de infecções hospitalares. Durante a observação, tanto do pessoal de enfermagem como dos residentes e estudantes de medicina, essas duas medidas não foram obedecidas. Conforme verificamos pelas observações, alguns fatores têm contribuído para que a técnica não seja efetivada: as instalações de pias e torneiras não são apropriadas; falta material como toalhas descartáveis e sabão; o pessoal de enfermagem é insuficiente para o número de recém-nascidos que cuida e a lavagem freqüente das mãos aumenta o tempo dispendido em cada cuidado; o uso freqüente de solução degermante causa ressecamento à pele das mãos.

A qualificação profissional parece não ser fator que diferencie o comportamento, porque tanto a auxiliar de enfermagem como o residente de medicina não lavam as mãos, conforme é recomendado. Logo, não se trata de desconhecimento de medidas profiláticas para prevenir infecções. Acresce-se que há avisos nas paredes, lembrando esta regra. Estes fatos nos levam a questionar a eficácia da educação continuada, uma vez que o problema não está em desconhecer as conseqüências de infringir as medidas profiláticas.

Em nossa opinião, pela observação e experiência na unidade em estudo, a lavagem das mãos sistemática entre os cuidados prestados a cada recémnascido, depende de instalações adequadas, material de consumo como sabão e toalhas de boa qualidade, tempo razoável para o pessoal de enfermagem prestar os cuidados e uma supervisão constante e enérgica. Também seria interessante o envolvimento de todo o pessoal, médico e de enfermagem, nas discussões de caso clínico quando houvesse suspeita de infecção adquirida no hospital para melhorar a adequação entre as medidas prescritivas e as observadas.

\subsubsection{Instalação de torneiras, pias e cuidados}

Algumas torneiras da unidade não são adequadas, pois não têm haste ou outros meios para abri-las ou fecha-las sem o contato direto das mãos e, quando utilizadas, não observamos o uso de papel toalha descartável para seu fechamento. Estas torneiras estão instaladas na enfermaria de cuidados intensivos e de normais e prematuros. Na enfermaria de recém-nascidos normais e prematuros e na pia da ante-sala, as torneiras têm haste, mas não podem ser usadas conforme o preconizado porque estão mal instaladas, permanecendo encostadas na parede quando fechadas.

Em todas as enfermarias e na ante-sala há locais específicos para instalação de frascos de solução degermante para higiene das mãos. A solução utilizada é à base de iodo. Observamos que nem sempre o líquido está colocado no recipiente apropriado, o frasco é deixado sem a tampa, o líquido é despejado nas mãos e o restante volta ao frasco, podendo, pelo contato com as mãos, estar contaminado.

\subsection{Cuidados relativos ao pessoal contactante}

Em relação ao pessoal, observamos que a prescrição que pede que haja pessoal fixo só para trabalhar no berçário, é respeitada parcialmente. A equipe de enfermagem é fixa na unidade de berçário. Também passam pela unidade alunos do curso de graduação em 
enfermagem e do curso de auxiliar de enfermagem.

$\mathrm{Na}$ equipe médica há um rodízio dos residentes e graduandos em períodos, pela enfermaria de pediatria, berçário, alojamento conjunto e sala de recepção do recém-nascido.

Os aventais utilizados na unidade são confeccionados com mangas compridas. A equipe de enfermagem que atua diretamente com o recém-nascido utiliza-o com as mangas enroladas até a altura dos cotovelos.

O uso de aventais na unidade não parece ser de grande importância para algumas pessoas, principalmente, entre graduandos da medicina; observamos que o fazem de forma inadequada, ou seja, com as mangas compridas. Parece não perceberem que as mangas entram em contato com os recém-nascidos tornando-se veículo de uma infecção cruzada quando do atendimento de várias crianças. Por outro lado, algumas auxiliares de enfermagem procuram utilizar camisolas destinadas à pacientes, que não possuem mangas, provavelmente para terem mais mobilidade e não sentirem tanto calor, e não com a intenção de prevenirem infecção cruzada.

\subsection{Métodos de limpeza}

\subsection{1. Área física e instalações}

\section{Limpeza concorrente}

A limpeza e desinfecção da área física é feita no período da tarde pelo pessoal da limpeza - faxineiras, e pela manhã no final do plantão é realizada manutenção da limpeza. Durante nossa observação verificamos que o piso, algumas vezes, é limpo de acordo com o preconizado, utilizando-se a técnica do duplo balde e solução desinfetante $\mathrm{e}$, em outras, a água mal é despejada no chão e já em seguida é retirada. A unidade tem seu material de limpeza próprio como rodo, balde e pano de chão, sendo armazenado em expurgo exclusivo do berçário quando não está em uso.

\section{Limpeza Terminal}

A limpeza terminal não foi observada por não ter ocorrido durante o período de observação. Em entrevista com uma das faxineiras, verificamos que é uma atividade eventual e depende de uma determinação médica.

\section{Pias e lavabos}

O lavabo é limpo pelas faxineiras com solução desinfetante e um pano logo após a limpeza concorrente da unidade. Quanto às pias observamos a limpeza sendo feita pelo pessoal de enfermagem, após os banhos de rotina dos recém-nascidos, com uso de fraldas ou pedaços de pano que, muitas vezes, ficam sobre ela.

\subsubsection{Material permanente e equipamentos}

\section{Incubadoras}

As incubadoras têm sido usadas freqüentemente, na unidade, devido ao grande número de prematuros. Estas servem de isolamento protetor ou para evitar contaminação, além de terem outras funções. A limpeza é feita, após a higiene do recém-nascido, com detergente líquido, água e fralda ou pedaços de pano. Essa mesma fralda, quase sempre, já tinha sido utilizada em várias incubadoras. A higiene do recém-nascido é feita em dias alternados. Verificamos, portanto, que a incubadora não é limpa adequadamente, não atendendo as recomendações. A presença de poeira e pequenos objetos no interior da câmara das incubadoras é freqüente, revelando que a limpeza interna nem sempre é realizada.

\section{Berços}

Os berços são para uso individual, entretanto observamos que dois ou três recém-nascidos ocupavam o mesmo berço. Isto ocorreu, porque na enfermaria maior há somente um berço aquecido onde são colocados os recém-nascidos, logo que chegam do centro obstétrico, até estabilizarem a termorregulação e ser realizada a higiene corporal. Havendo mais de um nascimento, em pequeno espaço de tempo, os recémnascidos são logo encaminhados ao berçário e colocados juntos. Após o banho são colocados em berços comuns e individuais.

A limpeza é feita em todos os berços com água e detergente líquido. Notamos a utilização de um único pano para limpeza de todos os berços, sem observar os procedimentos prescritos e realizada pela auxiliar de enfermagem. Esta funcionária estava assistindo a sete recém-nascidos em um turno de trabalho. Já a enfermeira fez a limpeza utilizando material adequado e observando os passos da técnica. Observamos que a mesma estava cuidando de apenas um recém-nascido.

\section{Aspiradores de secreção}

Os frascos coletores de secreção devem ser trocados, diariamente, quando em uso. Durante a observação, verificamos que um frasco ficou alguns dias sem tratamento, chegando até a secar a secreção. Observamos em outro dia a troca dos frascos coletores e extensões. A secreção contida nos frascos era tratada com fenol sintético, desprezado o líquido e, em seguida, colocado o frasco em um saco plástico identificado para encaminhamento à Central de Material. As extensões de 
borracha foram colocadas em recipiente com solução de Hipoclorito à 1000 p.p.m. e encaminhadas para a descontamição.

\section{Ventiladores e respiradores}

A limpeza externa dos ventiladores e respiradores é feita somente com um pedaço de pano ou fralda, água e detergente líquido. A falta de material próprio para limpeza faz com que o pessoal de enfermagem utilize recursos para saná-la, como por exemplo, o uso de fraldas para a limpeza de materiais e equipamentos. As extensões são encaminhadas para a Central de Material onde são esterilizadas.

\section{Material para entubação endotraqueal} mesmo.

Não foi observada a limpeza e esterilização do

\subsubsection{Material descartável e de pronto uso}

\section{Agulhas}

As agulhas são descartáveis e, após o uso, são desprezadas em recipientes de plástico duro. Estes recipientes são frascos de soluções reaproveitados, mas apresentam um inconveniente, pois a abertura para depósito de material pérfuro-cortante é pequena, correndose o risco de ferimentos. Quando cheio estes frascos são substituídos pelo pessoal da limpeza.

\section{Seringas}

O uso de seringas descartáveis na unidade é freqüente, tanto para administração de medicamentos, como para alimentação por gavagem, instilação nasal e aspiração de sonda endotraqueal.

No caso de gavagem, observamos a reutilização de seringas pelas auxiliares de enfermagem, pelo menos duas vezes, sendo enxaguadas com água fervida e deixadas dentro das incubadoras ou protegidas com a própria embalagem sob os berços, após cada uso. Também são reutilizadas no caso de instilação nasal e aspiração de sonda endotraqueal, durante o plantão.

\section{Sondas nasogástricas e orogástricas}

A utilização de sondas naso ou orogástricas é bastante comum, principalmente em recém-nascidos prétermos, para alimentação. Durante nossa observação, verificamos a falta de sondas na unidade em alguns períodos, ocasionando uma permanência prolongada em alguns recém-nascidos, pois prioriza-se trocar a dos prematuros. Para sua substituição foram utilizadas sondas tipo retais de polietileno de material plástico mais duro. Estas sondas podem ficar até uma semana, mas a rigidez do material a torna mais traumática. Após o uso, estas sondas são lavadas em água corrente, retirados dos esparadrapos e fios, depositadas em um frasco de vidro, encaminhadas à Central de Material, para reesterilização.

\section{Lâmina para abrir frascos plásticos de soro}

As ampolas de soro fisiológico e água destilada utilizadas na unidade, durante o período de observação eram acondicionadas em embalagem plástica, necessitando serem abertas por lâminas esterilizadas. Esta lâmina esteve em falta por alguns períodos, exigindo ouso de agulha e seringa para aspirar a solução. Quando se conseguiu a lâmina própria, esterilizada e descartável, guardada após o uso, na própria embalagem. A falta do material próprio ocasiona desperdício de outros como a seringa e agulha descartáveis, neste caso.

\section{Mamadeiras}

As mamadeiras são distribuídas na unidade de três em três horas, em recipientes individuais, para serem administradas nos respectivos horários.

Para atender crianças internadas após a rotina de distribuição, ou as que eventualmente têm sua prescrição alterada, o lactário envia ao berçário mamadeiras com outras fórmulas lácteas que são denominadas de reservas. Estas são armazenadas por 24 horas na unidade. Caso seu conteúdo redistribuído em outras mamadeiras, adequando o volume à quantidade prescrita. Neste procedimento, há uma manipulação, que não obedece às técnicas de assepsia. Estas reservas após recondicionamento são aquecidas em banho-maria. A água deve ser trocada a cada vez que é aquecida. Como isso não acontece, fica turva, com resíduos de leite, favorecendo a contaminação.

A água fervida ou solução de glicose a $5 \%$, a ser administrada por via oral para hidratação nos intervalos das mamadas é distribuída uma vez ao dia permanecendo junto do berço durante 24 horas. A prescrição recomenda que a solução glicosada seja trocada a cada seis horas.

\section{Termômetros}

Há somente dois termômetros para atender 14 leitos. São deixados em um frasco de vidro com álcool a $70 \%$. Observamos que a limpeza não é feita, após a utilização em cada recém-nascido, ao passar para outro, podendo ocasionar uma infecção cruzada. 


\section{Otoscópios} foi utilizado.

Durante o período de observação o otoscópio não

\section{Estetoscópios}

Os estetoscópios são utilizados pelos médicos, durante o exame do recém-nascido e pela enfermagem, quando é realizada sondagem naso ou orogástrica. A utilização do aparelho, tanto pela enfermagem como pelos médicos, deu-se conforme o preconizado, limpando-o com álcool a 70\%, antes e após o uso em cada recém-nascido.

\section{Balanças}

Observamos que o uso da toalha de papel descartável para proteger a balança não está de acordo como prescrito na literatura, pois as duas faces da toalha são utilizadas para recém-nascidos diferentes. Sabemos que uma vez utilizada uma face, ao virar o papel, esta entra em contato com a almofada da balança, conseqüentemente 0 papel se contaminará se for reutilizado, mesmo virado e oferecida a outra face.

\section{Fita métrica}

A fita métrica também pode levar contaminação ao recém-nascido, quando não devidamente limpa. Observamos que a limpeza da mesma fica a desejar, pois é realizada somente antes de usar no recém-nascido.

\subsection{Cuidados relativos ao recém-nascido}

\section{Higiene do recém-nascido}

A higiene do recém-nascido, segundo a Academia Americana de Pediatria, é considerada necessária no sentido de prevenir infecções cruzadas. Recomenda-se que o banho seja dado no próprio berço utilizando material individual, manipulação mínima, secar bem o coto umbilical caso entre em contato com a água, não colocar o recém-nascido em mesas ou pias de uso coletivo.

Entretanto, observamos que o banho de todos os recém-nascidos, tanto o primeiro como os subseqüentes, são realizados na pia. O recém-nascido é colocado sobre as bordas de inox da pia, forrada com o lençol do próprio berço. Ali ele é ensaboado e enxaguado, encharcando o lençol. Após o banho de cada recém-nascido, o lençol é trocado, mas não é feita a limpeza da pia. O sabonete utilizado no banho é deixado sobre a pia e reutilizado para todos os recém-nascidos.

\section{Credeização}

Utiliza-se nitrato de prata a 1\% para prevenção de oftalmia gonocóccica. A credeização é realizada no Centro Obstétrico. A solução é acondicionada em frasco escuro trocado diariamente no plantão da manhã; o conta-gotas permanece imerso na solução, após ser utilizado. Preconiza-se que o conta-gotas seja individual, o que não acontece.

\section{Curativo umbilical}

Observamos que, para limpeza do coto umbilical utilizam-se cotonetes embebido com álcool a 70\%, conforme o preconizado.

\section{Cuidados relativos às roupas}

As roupas utilizadas pelos recém-nascidos são próprias do hospital. Chegam à unidade limpas, em sacos de tecido identificados e são armazenadas em armários telados, de ferro, com rodas e em armários de fórmica com portas. Observamos a grande falta de roupas na unidade, em todos os plantões. Essa falta compromete os cuidados com a prevenção de infecção. Além disso, quando faltam fraldas, lençóis são rasgados para substituí-las, o que piora a distribuição de roupas. Quando sujas, as roupas são depositadas em hampers forrados com saco de tecido e com saco plástico, sem tampa ou proteção.

\section{CONSIDERAÇÕES FINAIS}

Sintetizando, verificamos que, muitas das medidas prescritivas para prevenção de infecção hospitalar que encontramos na literatura, conforme já explicitado, não estão sendo observadas nas ações desempenhadas no berçário escolhido para estudo. As reflexões feitas a seguir procuram evidenciar as maiores dificuldades na prevenção de infecções encontradas neste estudo, e, como foi antecipado na metodologia, formular hipóteses e sugerir encaminhamentos que poderão ser testados e reformulados em outras investigações.

A planta física não favorece a acomodação dos berços e a distribuição de acordo com o preconizado. A enfermagem não mantém os berços fixos levando a uma aproximação excessiva entre eles, para facilitar a organização de seu trabalho, principalmente quando há superlotação no berçário. O controle do ar ambiente sofre com a instalação de aparelhos de ar condicionado de parede que são inadequados para manter o ambiente livre de contaminação, como descrito.

A lavagem das mãos também não está sendo 
observada como deveria, devido à instalação inadequada de torneiras e pias, falta de material descartável de boa qualidade, e pela resistência do pessoal no cumprimento desta medida.

A recomendação de fixar pessoal não é obedecida, havendo uma circulação de pessoas de outras áreas dentro de berçário, que não estão preparadas para adotarem as medidas técnicas preventivas de infecção como deveriam.

A limpeza de equipamentos e material de berçário feita pelo pessoal de enfermagem requer ainda um aperfeiçoamento da técnica, porém, esse aperfeiçoamento só será possível se for fornecido material necessário, instrumentos, panos, líquidos próprios para fazer a higiene de cada berço individualmente evitando a utilização de fraldas e panos que estão ali para outros fins. Não é só uma questão de treinamento de pessoal, mas de fornecimento de material adequado.

Quanto aos ventiladores, respiradores, material descartável, eles estão de acordo com a prescrição. Entretanto, as seringas descartáveis para medicação via oral e alimentação de crianças são utilizadas e deixadas no meio ambiente.

As mamadeiras também não estão obedecendo às prescrições de uso individual, pois estão sendo manipuladas dentro da enfermaria, conforme descrito.

A primeira hipótese formulada é a seguinte: o cumprimento das medidas profiláticas não pode ser analisado parceladamente. Elas se constituem numa rede de procedimentos interdependentes e a quebra de uma delas desencadeia uma sucessão de infrações às outras regras.

A planta física precisa ser planejada de forma a possibilitar todas as instalações necessárias a prevenção de infecções. O equipamento e material de consumo, também, desempenham papel importante na prevenção de infecções; a falta de roupa, material de consumo descartável como seringas, sondas, toalhas, material de limpeza, sabão, entre outros favorece a contaminação e, ainda, proporciona ao pessoal uma desculpa para justificar o descuido na aplicação de outras medidas profiláticas, que não dependem diretamente do material em questão. A qualidade do material é importante. Sabões que ressecam as mãos servem de desculpa ou pretexto para não se lavar as mãos. Então, se o material não é de qualidade, ele desqualifica todo o restante do trabalho.

Quanto aos recursos humanos, vários fatores podem ser levantados: falta uma política que valorize o pessoal de enfermagem, proporcionando educação continuada, especializações, remuneração condizente com a responsabilidade que assumem. Por tudo isto, há uma grande rotatividade de funcionários e desgaste da força de trabalho, com muitos fazendo horas extras. Nas entrevistas verificou-se que eles conhecem as regras e prescrições de prevenção de infecções, porém não conseguem colocá-las em prática, por excesso de crianças para cuidar, falta de tempo, de material ou de condições adequadas.

Seu aperfeiçoamento deve ser acompanhado de unia valorização na carreira, de um trabalho de equipe, no qual todos se sintam co-participantes dos resultados. Uma simples advertência ou chamadas feitas em passagem de plantão, em pequenas reuniões informais, parece não estarem surtindo efeitos no berçário em questão. A nossa sugestão é que esses treinamentos devam ser formalizados e aceitos pela instituição como uma qualificação profissional que revertesse numa melhoria salarial. Um funcionário especializado teria não só uma compensação financeira, mas um reconhecimento dentro da equipe pela sua co-participação na responsabilidade de prevenir infecções e de atuar na assistência ao recémnascido como um membro que contribui no processo coletivo de trabalho. Eles precisariam participar de um trabalho de equipe, no qual todos se sentissem responsáveis e comprometidos com essa cadeia de medidas profiláticas. A administração do hospital também precisa ser envolvida neste processo, oferecendo a estrutura necessária. Caso contrário todo o processo de prevenção de infecções hospitalares ficará prejudicado.

Outra reflexão necessária é sobre a hierarquia que valoriza mais a medicação do que os cuidados como um todo. Foi observada a priorização de algumas medidas em detrimento de outras. Para dar medicação à todas às crianças dentro do horário, deixam de lavar as mãos entre a administração de um medicamento e outro, a diferentes crianças. Alegam que dar o remédio e economizar tempo é mais importante do que lavar as mãos, como se o antibiótico pudesse sanar todos os efeitos de uma falta de rigor na prevenção de infecção. Então, se deposita muito valor na medida terapêutica medicamentosa não dando uma atenção maior a todos os procedimentos que em conjunto vão constituir uma assistência mais criteriosa.

No depoimento de cada funcionário há critérios de prioridade nesta cadeia de medidas profiláticas. A quebra de uma das medidas pode prejudicar todas as outras; observamos que a superlotação do berçário é o ponto mais suscetível e quando ela ocorre, todas as outras medidas aparecem em suas falas e atitudes como dispensáveis.

Assim, concluímos que as medidas de prevenção têm que ser tomadas em conjunto, num complexo de atividades, fundamentadas em instalações e estrutura adequadas, desempenhadas por uma equipe profissional coesa, onde todos trabalhem com os mesmos objetivos. Tomá-las isoladamente não contribui para o efetivo cumprimento das prescrições. 


\section{NURSING CARE IN NEONATAL UNITS: MEASURES FOR THE PREVENTION OF HOSPITAL INFECTIONS}

The prevention of infection in nurseries requires measures related to nursing care in terms of the environment, equipment, personnel and the newborn. In view of the problems related to hospital infection, the objective of the present investigation was lo determine the relationship between prescriptive measures for the Prevention of Infection and activities effectively carried out in a Neonatal Admission Unit. Participant observation and semi structured interviews were the strategies used for the investigation which allowed data collection. With this research we could see that prophylactic measures need to be taken together in a collection of activities based on adequate structure and facilities, performed by a cohesive professional team where everybody work towards the same goal. Measures taken isolated do not contribute lo the effective accomplishment of prescriptions.

\section{ASISTENCIA DE ENFERMERÍA EN UNIDADES DE HOSPITALIZACIÓN NEONATAL: MEDIDAS PARA PREVENCIÓN DE INFECCIONES HOSPITALARIAS}

La prevención de infección en salas de recién nacidos, referentes a la asistencia de enfermería, requiere cuidados con el ambiente, equipos, personal y con el propio recién nacido. Frente a los problemas relacionados con la infección hospitalaria encontrados, esta investigación tiene por objetivo verificar la relación entre las medidas prescriptivas sobre la prevención de la infección y las actividades efectivas realizadas en una unidad de intervención neo-natal. Las estrategias de investigación adoptadas, fueron, la observación participante y la entrevista semi-estructurada, posibilitando la colecta de datos. Con este trabajo pudimos ver que las medidas profilácticas tienen que ser tomadas en un conjunto de actividades, basadas en instalaciones y estructuras adecuadas, ejecutadas por un equipo profesional en que todos trabajan con los mismos objetivos. Tomálas aisladamente no contribuye para el efectivo cumplimiento de las prescripciones.

TÉRMINOS CLAVES: infección hospitalaria, recién nacido, asistencia de enfermería, sala de recién nacido, neonatología

\section{REFERÊNCIAS BIBLIOGRÁFICAS}

01. ACADEMIA AMERICANA DE PEDIATRÍA. Normas y recomendaciones para la atención del recién nacido en hospitales a término y prematuro. Illinois: Nestlé, 1957.

02. AMERICAN ACADEMY OF PEDIATRICS. Standards and recommendations for hospital care of newborn infants full: term and premature. 2.ed. Illinois, 1954.

03.

Standards and recommendations for hospital care of newborn infants. 5. ed. Illinois, 1974.

04.

Standards and recommendations for hospital care of newborn infants. 6.ed. Illinois, 1977.

05. BRASIL. Ministério da Saúde. Secretaria Geral. Legislação brasileira sobre infecção hospitalar. Brasília: Ministério da Saúde/Centro de Documentação do Ministério da Saúde, 1985. 313p. (Série E. Legislação de Saúde, n²).

06. CENTRO DE ESTUDOS PERINATAIS DE SÃO PAULO-CEPENSP. Rotinas de assistência em hospital ao recém-nascido normal, prematuro e de baixo peso. São Paulo, 1966.

07. CLONEY, D.L.; DONOWITZ, L.G. Overgown use for infection control in nurseries and neonatal intensive care units. AJDC, v. 140, p. 680-3, 1986.
08. DONO WITZ, L.G. Nosocomial infection in neonatal intensive care units. Am. J. Infect. Control., v. 17, p. 250-7, 1989.

09. GORDON, H.H. Perspectivas em neonatologia: 1980. In: AVERY, G.B. Neonatologia: fisiopatologia e tratamento do recém-nascido. 2.ed. Rio de Janeiro: MEDSI, 1984. cap. 1, p. 3-12.

10. KAMADA, I. A organização dos berçários e o processo de trabalho da enfermagem. Ribeirão Preto, 1991. 77p. (datilografado).

11.KLEIN, J.O.; REMJNGTON, J.S.; MARCY, S.M. Current concepts of infections of the fetus and newborn infant. In: REMINGTON, J.S.; KLEIN, J.O. Infectious diseases of the fetus and newborn infant. 2 ed. Philadelphia; W.B. Saunders, 1983. Cap. 1, p. 1-26.

12. LOYOLA, A. A cultura da puericultura. Rev. Novos Estudos CEBRAP, v.l, n.1/2, p. 40-46, 1983.

13. MINAYO, M.C.S. O desafio do conhecimento: metodologia de pesquisa social (qualitativa) em saúde. Rio de Janeiro, 1989. 1366p. Tese (Doutorado) - Fundação Oswaldo Cruz.

14. NELSON, J.D. Control of infection acquired in the nursery. In: REMINGTON, J.S.; KLEIN, J.O. Infectious diseases of the fetus and newborn infant. 2.ed. Philadelphia: N.B. Sounds, 1983. cap. 29, p. 1035-1052. 
15. Oliveira, S. Rotura prematura das membranas e infecção no recém-nascido. Ribeirão Preto, 1983. 94p. Dissertação (Mestrado)-Faculdade de Medicina de Ribeirão Preto, Universidade de São Paulo.

16. PIZZATO, M.G.; DA POIAN, V.R.L. Enfermagem neonatológica. 2.ed. Porto Alegre: D.C. Luzzatto, 1988.

17. ROBERTON, N.R.C. A Manual of neonatal intensive care. 2.ed. London: Hodder \& Stoughton., 1986.

18. SÃO PAULO (Estado). Secretaria de Estado da Saúde. Berçário de recém-nascidos: recomendações básicas para sua instalação e funcionamento. São Paulo: Instituto de Saúde, 1976. p.93.
19. SÃO PAULO (Estado). Secretaria de Estado da Saúde. Recomendações para padronização da assistência hospitalar ao recém-nascido. Diário Oficial do Estado-DOE. São Paulo: Departamento Técnicas. Quinta-feira, 2 abr. 1981. Seção 1.

20. SÃO PAULO (Estado). Secretaria de Estado da Saúde. Infecção em berçário: informes técnicos. São Paulo, v. 2, n. 11, p. 2-8, fevereiro 1991. (Grupo de Infecção Hospitalar: Informação $n^{\circ} 21$ ).

21. VÉRAS, J.F.C.et al. Manual de enfermagem. 2.ed. Serra do Navio - T.F.A.: ICOMI. Industria e Comércio de Minérios. Divisão de Saúde, 1965.

22. ZANON, U. Infecções hospitalares: prevenção, diagnóstico e tratamento. Rio de Janeiro: MEDSI, 1987. 


\section{ANEXO 1}

Figura 1 - Planta baixa do Berçário

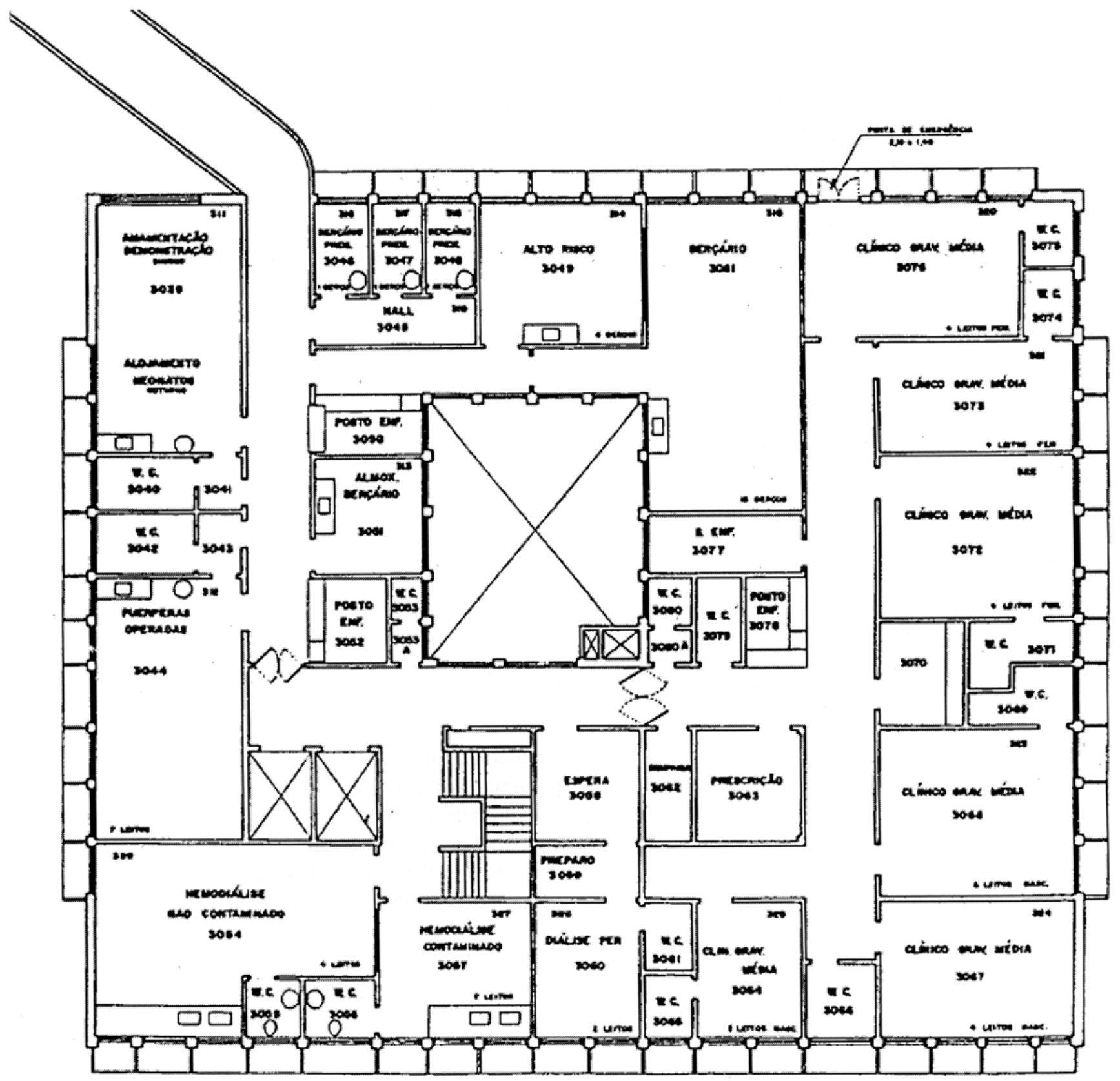

BLOCO - B 


\section{ANEXO 2}

\section{Protocolo de observação (modelo)}

\begin{tabular}{|c|c|}
\hline Procedimentos Prescritos na Literatura & *Procedimentos Observados \\
\hline 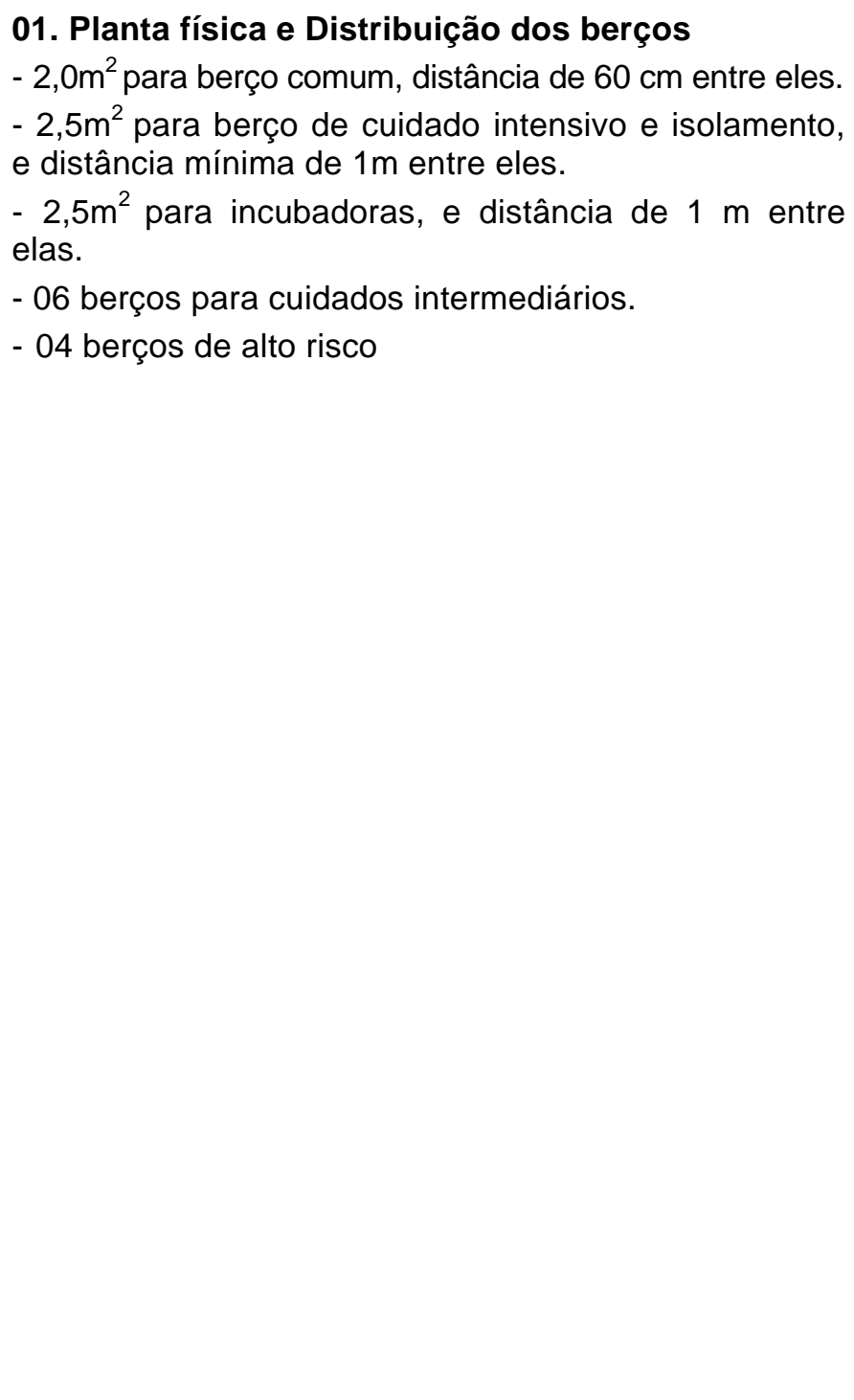 & $\begin{array}{l}\text { - A enfermaria } 315 \text { é dividida por um balcão que atende, } \\
\text { de um lado recém-nascidos normais, de outro os } \\
\text { prematuros. } \\
\text { - Observamos que a enfermaria } 315 \text { contava com } 07 \\
\text { incubadoras de um lado e de outro } 05 \text { berços comuns, } \\
01 \text { aquecido e } 04 \text { incubadoras, contando um total de } 17 \\
\text { leitos com distância entre eles de, aproximadamente } 50 \\
\text { cm. } \\
\text { - } 09 \text { incubadoras (prematuros), } 07 \text { berços comuns, } 02 \\
\text { incubadoras, } 01 \text { aquecido e } 04 \text { berços vazios, num total } \\
\text { de } 23 \text { leitos. A distância entre os berços é de, } \\
\text { aproximadamente, } 20 \text { cm. } \\
\text { - } 07 \text { incubadoras (prematuros), } 01 \text { incubadora, } 08 \\
\text { berços comuns e } 01 \text { aquecido, num total de } 18 \text { leitos. } \\
\text { Distância entre os berços comuns } \\
\text { aproximadamente, } 50 \text { cm, entre as incubadoras de } 10 \\
\text { cm. } \\
\text { - } 08 \text { incubadoras (prematuros), } 01 \text { incubadora, } 14 \\
\text { berços comuns e } 01 \text { aquecido, num total de } 24 \text { leitos. } \\
\text { Distância entre os berços de, aproximadamente, } 20 \mathrm{~cm} \\
\text { e incubadoras } 20 \mathrm{~cm} \text {. } \\
\text { - } 09 \text { incubadoras (prematuros), } 01 \text { incubadora, } 01 \text { berço } \\
\text { aquecido e } 14 \text { berços comuns, num total de } 25 \text { leitos. } \\
\text { Distância entre os berços de, aproximadamente, } 05 \text { a } \\
20 \text { cm, e incubadoras de } 20 \mathrm{~cm} \text {. } \\
\text { - } 07 \text { incubadoras (prematuros), } 07 \text { berços comuns e } 01 \\
\text { aquecido, num total de } 15 \text { leitos na enfermaria de } \\
\text { prematuros e normais com distância entre os berços } \\
\text { comuns de, aproximadamente, } 20 \text { cm, entre as } \\
\text { incubadoras de } 50 \mathrm{~cm} \text {, e entre os berços CTI } 02 \mathrm{~m} \text {. } \\
\text { - } 03 \text { berços CTI na Unidade de alto risco, com distância } \\
\text { entre eles de } 02 \mathrm{~m} \text {. } \\
\text { - Enfermaria } 316 \text { com } 01 \text { berço comum em cada } \\
\text { unidade de isolamento. }\end{array}$ \\
\hline
\end{tabular}

